\title{
SUBSTRATOS ALTERNATIVOS NO CRESCIMENTO INICIAL DE MUDAS DE CASSIA GRANDIS L. F
} Ângela Santos de Jesus Cavalcante dos Anjos ${ }^{1}$, Rafaela Simão Abrahão Nóbrega ${ }^{2 *}$ Flávia Melo
Moreira $^{3}$, Janildes de Jesus da Silva ${ }^{1}$, Caliane da Silva Braulio ${ }^{1}$, Júlio César Azevedo Nóbrega ${ }^{2}$

RESUMO - A utilização de resíduos orgânicos agropecuários e agroindustriais para compor os substratos de cultivo pode ser uma alternativa viável para a produção de mudas de qualidade. Diante disso, objetivou-se avaliar o efeito de proporções e resíduos orgânicos na formulação de substratos para a produção de mudas de Cassia grandis L. f. O experimento foi conduzido em casa de vegetação, sendo disposto em delineamento experimental inteiramente casualizado em esquema fatorial ( 2 x 5), com oito repetições, constituídos com dois tipos de resíduos (resíduo de fibras de Agave sisalana e o composto orgânico de poda de árvore e esterco bovino e caprino), combinados com Neossolo Quartzarênico e homogeneizados em cinco porcentagens de resíduos orgânicos $(0,20,40,60$ e 80\%). Após 90 dias da semeadura, avaliaram-se: altura da planta, diâmetro do colo, número de folhas, comprimento da raiz, massa seca da parte aérea, raiz e total, relação entre altura e diâmetro do caule, relação altura e massa seca da parte aérea, relação massa seca da parte aérea e massa seca da raiz e o Índice de Qualidade de Dickson. O uso de substratos constituídos por proporções de resíduo da extração de fibras de Agave sisalana e o composto orgânico de poda de árvore acrescido de esterco bovino e caprino acondicionados a Neossolo Quartzarênico não promovem efeito no crescimento inicial de Cassia grandis L. f. As mudas de Cassia grandis L. f. cultivadas em substrato constituído apenas com Neossolo Quartzarênico apresentam maior Índice de Qualidade de Dickson.

Palavras chave: composto orgânico, produção de mudas, resíduos de fibras de Agave sisalana.

\section{ALTERNATIVE SUBSTRATES IN THE INITIAL GROWTH OF CHANNELS Cassia grandis $L$. F}

\begin{abstract}
The use of organic agricultural and agroindustrial residues to compose the cultivation substrates can be a viable alternative for the production of quality seedlings. The objective of this study was to evaluate the effect of proportions and organic residues on the formulation of substrates for the production of Cassia grandis $L . f$. The experiment was conducted in a greenhouse, being arranged in a completely randomized experimental design in a factorial scheme $(2 \times 5)$, with eight replicates, consisting of two types of residues (Agave sisalana fiber residue and the organic tree pruning compound and bovine manure and goat manure), combined with Quartzarenic Neosol and homogenized in five percentage of organic waste $(0,20,40,60$ and $80 \%)$. After 90 days of sowing, plant height, leaf diameter, number of leaves, root length, shoot dry mass, root and total, height-stem diameter ratio, height and dry mass ratio were evaluated aerial part, shoot dry matter ratio and root dry mass, and the Dickson Quality Index. The use of substrates made up of residue proportions of Agave sisalana fiber extraction and organic pruning compound plus bovine and goat manure conditioned to Quartzarenic Neosol did not promote effect on the initial growth of Cassia grandis L.f. The seedlings of Cassia grandis L.f. cultivated on substratum constituted only with Quartzarenic Neosol present higher Dickson Quality Index.
\end{abstract}

Keywords: fiber waste of Agave sisalana, organic compound, production of seedlings.

\footnotetext{
${ }^{1}$ Discentes do Programa de Pós-Graduação em Solos e Qualidade de Ecossistemas - UFRB.

${ }^{2}$ Docentes do Centro de Ciências Agrárias, Ambientais e Biológicas (CCAAB) - UFRB, Cruz das Almas, BA, Brasil. *E-mail: rafaela.nobrega@gmail.com. Autor para correspondência.

${ }^{3}$ Discente do Programa de Pós-Graduação em Agronomia - UESB.
} 


\section{INTRODUÇÃO}

Com a necessidade de reabilitação e recuperação de ecossistemas degradados surge à necessidade de preservação e implantação de novas áreas de florestas. As espécies arbóreas de rápido crescimento, rústicas e fixadoras de nitrogênio podem ser uma alternativa viável (Delamerina et al., 2014; Fernandes et al., 2017). Para esses fins, dentre as espécies com grande importância para arborização urbana e em projetos de reflorestamento para recuperação ambiental está a Cassia grandis L. f. leguminosa de rápido crescimento, pertence à família Fabaceae (Lorenzi, 2008), que ocorre nas regiões tropicais e subtropicais do globo (Bezerra et al., 2012) e em solos ácidos (Freitas et al., 2017).

Para a produção de mudas de espécies arbóreas, a utilização de resíduos orgânicos como matéria-prima para a elaboração de substratos de cultivo pode resultar em diminuição dos custos de produção, por utilizar resíduos agropecuários e agroindustriais disponíveis na região, redução da utilização de insumos químicos e aumento na disponibilidade de nutrientes às plantas (Trazzi et al., 2012; Ferreira et al., 2015). Logo, o substrato para a produção de mudas tem por finalidade garantir o desenvolvimento de mudas de qualidade em curto período de tempo, com baixo custo e que sejam capazes de atender aos objetivos dos plantios para implantação de áreas degradadas (Kratka \& Correia, 2015). No entanto, existe uma demanda por informações sobre a utilização de diferentes materiais na formulação de substratos.

Dentre os resíduos agropecuários e agroindustriais, há o composto orgânico de poda de árvore acrescido de esterco bovino e caprino (Moreira, 2016), e o resíduos da extração de fibras de Agave sisalana, que é um material proveniente do processo de desfibramento das folhas (Pereira et al., 2017). As fibras de Agave sisalana representam somente $4 \%$ do seu peso, são usadas na fabricação de cordas, tapetes e outros produtos. Os $96 \%$ restantes são constituídos por resíduo líquido e o bagaço que são resíduos que podem ser utilizados como matéria prima abundante e barata (Pizarro et al., 1999). Com isso, o reaproveitamento destes resíduos orgânicos na agricultura e em áreas florestais tornouse uma alternativa promissora e sustentável ao descarte dos mesmos, reduzindo seu acúmulo no ambiente, além de agregar valor às atividades agrícolas em regiões produtoras de Agave sisalana.
O uso de resíduos orgânicos como componente de substratos para produção de mudas florestais foram relatados por Guimarães et al. (2013), que observaram maior crescimento de mudas de Pithecellobium dulce quando cultivadas em esterco bovino + areia, na proporção 2:1; Costa et al. (2015) concluíram que a adição de 10, 20 ou 30 de esterco ao substrato de cultivo proporcionaram melhores mudas de Dipteryx alata Vog; Duarte \& Nunes (2012) obtiveram mudas de Bauhinia forficata de qualidade quando cultivadas em substrato constituído por composto orgânico + terra de subsolo na proporção 1:1; Moreira (2016) recomendam substratos formulados com $33 \%$ de composto de poda de árvore + esterco animal ou $5 \%$ de resíduo da extração de fibras de Agave sisalana misturados a solo para a produção de mudas de Caesalpinia pulcherrima L. Sw.

Com a hipótese de que resíduos oriundos da extração de fibras de Agave sisalana e composto orgânico de poda de árvore acrescido de esterco bovino e caprino podem ser utilizados em formulações a partir de amostras de subsolo para compor substratos destinados ao cultivo de mudas de espécies arbóreas, objetivou-se avaliar o efeito de proporções e resíduos orgânicos na formulação de substratos para a produção de mudas de Cassia grandis L. f.

\section{MATERIAL E MÉTODOS}

O experimento foi conduzido em casa de vegetação da Universidade Federal do Recôncavo da Bahia (UFRB), no Centro de Ciências Agrárias, Ambientais e Biológicas (CCAAB), município de Cruz das Almas - BA. Coordenadas geográficas $12^{\circ} 40^{\prime} 19^{\prime \prime} \mathrm{S} \mathrm{e} 39^{\circ} 06^{\prime} 23^{\prime \prime} \mathrm{W}$. A classificação do clima é Af de acordo com a Köppen, com média anual de $23^{\circ} \mathrm{C}$.

Os tratamentos foram constituídos por dois tipos de resíduos (RES - resíduo da extração de fibras de Agave sisalana; COP - composto orgânico de poda de árvore e esterco bovino e caprino) combinados com solo, e homogeneizados em cinco porcentagens de resíduos orgânicos $(0,20,40,60$ e $80 \%)$, sendo dispostos em delineamento experimental inteiramente casualizado, e arranjados em esquema fatorial ( 2 x 5), com oito repetições.

O solo utilizado para compor o substrato foi o Neossolo Quartzarênico, coletado da camada subsuperficial ( $>40 \mathrm{~cm}$ de profundidade) no município de Entre Rios - BA. O composto orgânico de poda foi 
oriundo da pilha de compostagem da Superintendência de Infraestrutura e Planejamento do Espaço Físico (SIPEF) - UFRB, contendo em sua composição resíduo de poda de árvores e jardins, esterco bovino e caprino, numa relação 3:1:1. O resíduo de Agave sisalana (sisal) foi coletado na Região Semiárida, do município de Valente - BA, sendo oriundo do processo industrial da extração das fibras de sisal pré-fermentado 'in loco', sem algum manejo específico.

O solo e os resíduos foram secos ao ar, tamisados em peneira com malha de $4 \mathrm{~mm}$ e retiradas amostras para posterior análise química, homogeneizados de acordo aos tratamentos e acondicionados em sacos de polietileno com dimensões de 0,12 x 0,23 m e capacidade para $1,2 \mathrm{dm}^{-3}$.

As caracterizações químicas e físicas dos resíduos orgânicos (Tabela 1) e do solo foram realizadas por Moreira (2016) e estão aqui apresentadas, pois do mesmo lote caracterizado, foram retiradas as amostras para execução do presente estudo. A caracterização química do solo indicou: $\mathrm{pH}\left(\mathrm{H}_{2} \mathrm{O}\right): 5,5 ; \mathrm{pH}\left(\mathrm{CaCl}_{2}\right)$ :
4,8; P: $12,1 \mathrm{mg} \mathrm{dm}^{-3} ; \mathrm{Al}^{3+}: 0,2 \mathrm{cmol}_{\mathrm{c}} \mathrm{dm}^{-3} ; \mathrm{H}+\mathrm{Al}: 0,7 \mathrm{cmol}_{\mathrm{c}}$ $\mathrm{dm}^{-3}$; M.O.: $<3,5 \mathrm{~g} \mathrm{~kg}^{-1}$; Areia: $922 \mathrm{~g} \mathrm{~kg}^{-1}$; Silte: $47 \mathrm{~g} \mathrm{~kg}^{-1}$; Argila: $31 \mathrm{~g} \mathrm{~kg}^{-1}$; Umidade a-10 kPa: $0,018 \mathrm{~m}^{3} \mathrm{~m}^{-3}$ (Moreira, 2016).

As sementes de C. grandis foram coletadas em quinze árvores matrizes presentes na UFRB, durante os meses de fevereiro a março de 2016. Estas foram beneficiadas manualmente, retirando-se as danificadas. Após o beneficiamento, as sementes foram imersas em ácido sulfúrico (95 - 97\% P.A.) durante 60 minutos (Silva et al., 2012) para quebra de dormência, e posteriormente, lavadas em água e semeadas em sacos de polietileno com dimensões de $0,12 \times 0,23$ m e capacidade para 1,2 $\mathrm{dm}^{-3}$, sendo dispostas três sementes/saco. As regas e observações eram realizadas diariamente, com remoção manual de plantas espontâneas quando necessário.

O desbaste das plantas foi realizado após 30 dias da semeadura, deixando uma planta/saco. Aos 90 dias após a semeadura, as mudas foram avaliadas quanto às seguintes variáveis: altura da planta $(\mathrm{H})$, diâmetro

Tabela 1 - Caracterização química e física dos resíduos [COP (composto orgânico de poda de árvore e esterco bovino e caprino) e RES (resíduo da extração de fibras de Agave sisalana)], utilizados na composição de substratos orgânicos para crescimento inicial de mudas de Cassia grandis L. f.

\begin{tabular}{|c|c|c|}
\hline Atributos químicos e físicos ${ }^{1}$ & COP (base úmida) & RES (base úmida) \\
\hline $\mathrm{pH}\left(\mathrm{H}_{2} \mathrm{O}\right)^{1}$ & 7,0 & 9,6 \\
\hline $\mathrm{pH}\left(\mathrm{CaCl}_{2} 0,01 \mathrm{M}\right)$ & 6,4 & 8,7 \\
\hline Densidade $\left(\mathrm{g} \mathrm{cm}^{-3}\right)$ & 1,00 & 0,20 \\
\hline Umidade a $60-65^{\circ} \mathrm{C}(\%)$ & 12,03 & 41,53 \\
\hline Umidade a $110^{\circ} \mathrm{C}(\%)$ & 0,69 & 3,53 \\
\hline Matéria orgânica (Combustão) (\%) & 10,64 & 31,71 \\
\hline Carbono orgânico (\%) & 5,27 & 16,57 \\
\hline Resíduo mineral total (R.M.T.) (\%) & 76,64 & 23,24 \\
\hline Resíduo mineral (R.M.) (\%) & 5,76 & 20,27 \\
\hline Resíduo mineral insolúvel (R.M.I.) (\%) & 70,88 & 2,97 \\
\hline Nitrogênio total (NT) $(\%)$ & 0,62 & 1,47 \\
\hline Fósforo $\left(\mathrm{P}_{2} \mathrm{O}_{5}\right)$ total $(\%)$ & 0,20 & 2,05 \\
\hline Potássio $\left(\mathrm{K}_{2} \mathrm{O}\right)$ total $(\%)$ & 0,22 & 0,74 \\
\hline Cálcio $(\mathrm{Ca})$ total $(\%)$ & 0,50 & 4,97 \\
\hline Magnésio $(\mathrm{Mg})$ total & 0,11 & 0,98 \\
\hline Enxofre $(\mathrm{S})$ total $(\%)$ & 0,02 & 0,11 \\
\hline Relação C/N & 9 & 11 \\
\hline Cobre $(\mathrm{Cu})\left(\mathrm{mg} \mathrm{kg}^{-1}\right)$ & 13 & 54 \\
\hline Manganês $(\mathrm{Mn})\left(\mathrm{mg} \mathrm{kg}^{-1}\right)$ & 112 & 80 \\
\hline $\operatorname{Zinco}(\mathrm{Zn})\left(\mathrm{mg} \mathrm{kg}^{-1}\right)$ & 31 & 64 \\
\hline Boro (B) $\left(\mathrm{mg} \mathrm{kg}^{-1}\right)$ & 206 & 10 \\
\hline Sódio (Na) (mg kg $\left.{ }^{-1}\right)$ & 725 & 242 \\
\hline
\end{tabular}

${ }^{1}$ Dados extraídos de Moreira (2016). 
do colo (DC), número de folhas (NF) e comprimento da raiz (CR). As plantas foram lavadas e segmentadas em parte aérea e radicular, secas em estufa de circulação de ar forçado a $60^{\circ} \mathrm{C}$ por 72 horas e mensuradas quanto à massa seca da parte aérea (MSPA), massa seca de raízes (MSR) e suas relações massa seca total (MST), relação entre altura e diâmetro do colo (H/DC), altura e massa seca da parte aérea (H/MSPA), massa seca da parte aérea e massa seca de raízes (MSPA/MSR) e o Índice de Qualidade de Dickson (IQD) (Dickson et al., 1960). O Índice de Qualidade de Dickson foi obtido através da seguinte equação: IQD=MST $(\mathrm{g}) /[\mathrm{H}(\mathrm{cm}) /$ $\mathrm{DC}(\mathrm{mm})+\mathrm{MSR}(\mathrm{g}) / \mathrm{MSPA}(\mathrm{g})]$ (Dickson et al., 1960).

Os dados obtidos foram submetidos à análise de variância pelo teste $\mathrm{F}$ e comparação de médias pelo teste de Tukey a $5 \%$ de probabilidade. Os dados quantitativos foram submetidos posteriormente à análise de regressão polinomial para calcular o percentual ótimo de resíduo a ser utilizado no substrato para cada variável morfológica. As equações foram selecionadas em função da significância dos parâmetros, teste $\mathrm{F}$, o significado biológico e o coeficiente de determinação $\left(\mathrm{R}^{2}\right)$. Por meio do programa estatístico SISVAR (Ferreira, 2014).

\section{RESULTADOS E DISCUSSÃO}

Os tipos de resíduos e suas proporções influenciaram significativamente as variáveis morfológicas DC, CR, NF, MSPA, MSR e suas relações MST, H/MSPA, MSPA/R e IQD das mudas de Cassia grandis L. f (Tabela 2).

Verificou-se efeito individual $(\mathrm{P}<0,05)$ das proporções de resíduos para a variável DC (Tabela 2). O aumento das proporções de resíduo no substrato reduziu de maneira linear o DC das mudas, sendo verificado redução de $0,005938 \mathrm{~mm}$ planta $^{-1}$ para cada incremento unitário do percentual de resíduo. De modo que houve uma redução de $19 \%$ para maior proporção de resíduo testada ( $80 \%$ ) em relação a não utilização dos resíduos ( $0 \%$ ) (Figura 1). O DC é uma característica que tende a indicar a resistência das mudas ao tombamento em condições de campo.

Redução do DC com adição de resíduos orgânicos nos substratos de cultivo já foram reportados para as espécies florestais Eugenia dysenterica, Hancornia speciosa Gomes e Dipteryx alata Vog., aos 180 dias após a semeadura, sob condições controladas (Paiva Sobrinho et al., 2010). Mesmo efeito para a espécie

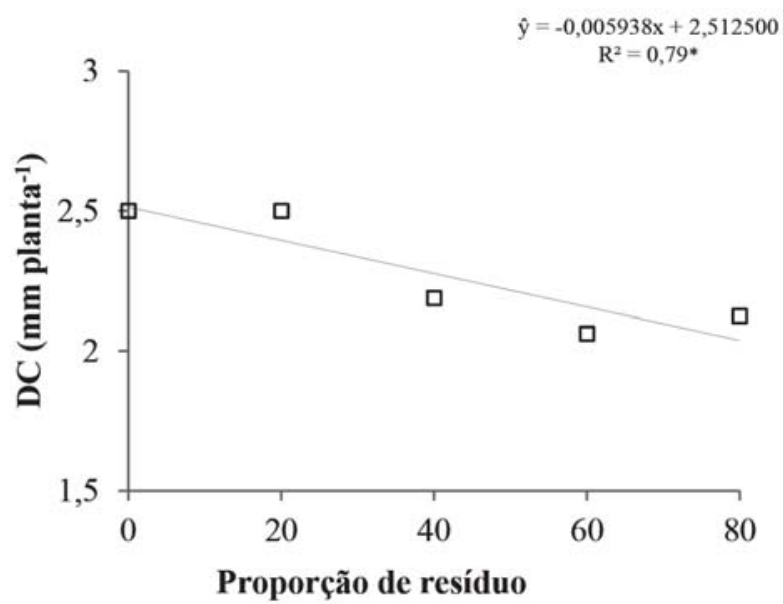

Figura 1 - Diâmetro do colo (DC) de mudas de Cassia grandis L. f, aos 90 dias após a semeadura, cultivadas em diferentes proporções de resíduo.

Tabela 2 - Resumo do quadro da análise de variância das características morfológicas e suas relações de mudas de Cassia grandis L. f., aos 90 dias após a semeadura, cultivadas em substratos constituídos por diferentes tipos e proporções de resíduos orgânicos

\begin{tabular}{|c|c|c|c|c|c|c|c|c|c|c|c|}
\hline \multirow{2}{*}{$\mathrm{FV}^{1}$} & \multirow{2}{*}{$\mathrm{GL}^{2}$} & \multicolumn{10}{|c|}{ Quadrado médio } \\
\hline & & $\mathrm{H}^{3}$ & $\mathrm{DC}^{4}$ & $\mathrm{NF}^{5}$ & $\mathrm{CR}^{6}$ & $\mathrm{MSPA}^{7}$ & $\mathrm{MSR}^{8}$ & MST $^{9}$ & $\mathrm{MSPA} / \mathrm{R}^{10}$ & $\mathrm{H} / \mathrm{MSPA}^{11}$ & $\mathrm{IQD}^{12}$ \\
\hline Resíduo(R) & 1 & $17,20^{\mathrm{ns}}$ & $0,80^{\text {ns }}$ & $0,50^{* *}$ & $115,68^{*}$ & $0,19^{* *}$ & $0,25^{* *}$ & $0,42^{* *}$ & $0,49^{* *}$ & $17,67^{* *}$ & $0,06^{* *}$ \\
\hline Proporção(P) & 4 & $5,19^{\mathrm{ns}}$ & $0,70^{*}$ & $0,14^{\mathrm{ns}}$ & $723,78^{* *}$ & $0,19^{* *}$ & $0,24^{* *}$ & $0,41^{* *}$ & $0,33^{* *}$ & $15,65^{* *}$ & $0,07^{* *}$ \\
\hline $\mathrm{R} \times \mathrm{P}$ & 4 & $8,32^{\mathrm{ns}}$ & $0,26^{\mathrm{ns}}$ & $0,07^{\mathrm{ns}}$ & $44,38^{\mathrm{ns}}$ & $0,05^{*}$ & $0,05^{* *}$ & $0,10^{* *}$ & $0,09^{\mathrm{ns}}$ & $1,46^{* *}$ & $0,01^{*}$ \\
\hline CV $(\%)$ & & 16,52 & 20,52 & 22,87 & 22,04 & 18,45 & 20,05 & 17,94 & 16,55 & 21,15 & 21,83 \\
\hline
\end{tabular}

${ }^{1} \mathrm{FV}$ : Fontes de variação; ${ }^{2} \mathrm{GL}$ : Grau de liberdade; ${ }^{3}$ Altura; ${ }^{4}$ Diâmetro do colo; ${ }^{5}$ Número de folhas; $;{ }^{6} \mathrm{Comprimento} \mathrm{da} \mathrm{raiz;}{ }^{7} \mathrm{Massa}$ seca da parte aérea; ${ }^{8}$ Massa seca de raiz; ${ }^{9}$ Massa seca total; ${ }^{10}$ Relação entre massa seca da parte aérea e massa seca de raiz; ${ }^{11}$ Relação entre altura e massa seca de parte aérea; ${ }^{12}$ Índice de qualidade de Dickson; ${ }^{\text {ns}}$ não significativo ao nível de $5 \%$ de probabilidade; $*$ Significativo $(\mathrm{P}<0,05)$; $* *$ Significativo $(\mathrm{P}<0,01)$. 
Hymenaea stigonocarpa cultivada em substratos orgânicos constituídos de bagana de carnaúba e esterco bovino, em que o DC também não foi influenciado pela adição de proporções destes resíduos nos substratos de cultivo (Lustosa Filho et al., 2015). Outra espécie não responsiva foi Eremanthus erythropappus em que aos 145 dias após a semeadura, sob condições controladas com a utilização de esterco bovino no substrato de cultivo, verificou-se a influência negativa da utilização de maiores proporções deste constituinte (Melo et al., 2014).

No presente estudo os resultados obtidos podem estar atribuídos às características químicas dos resíduos orgânicos utilizados para compor os substratos de cultivo, por apresentar alto teor de sódio $\left(\mathrm{Na}^{+}\right)$ (Higashikawa, 2009 apud Abad et a., 1992 e Cavins et al., 2000) (Tabela 1), causando desbalanço nutricional nos substratos de cultivo, o que proporcionou a planta um desenvolvimento abaixo do considerado normal que foi apresentado nas mudas cultivadas apenas com solo. O desbalanço nutricional resulta em inibição da absorção de outros cátions pela planta e competição pelos sítios de absorção nas raízes (Schossler et al., 2012). De acordo com o mesmo autor, o excesso dos sais de $\mathrm{Na}^{+}$, além de trazer perdas às propriedades físicas e químicas do solo, provoca à redução generalizada do crescimento das plantas cultivadas e reduz a sua capacidade de armazenar água e, consequentemente, sua absorção.

Trazzi et al. (2012) estudando os atributos físicos e químicos de estercos de origem animal, verificaram aumento na salinidade dos substratos, a medida que aumentou a quantidade dos estercos obteve-se aumento dos teores de $\mathrm{Na}^{+}$. Em estudos com substratos orgânicos na produção de mudas de Tectona grandis L. f., sob condições controladas, após 90 dias de semeadura, Trazzi et al. (2013) constataram que menores médias de DC foram observadas em plantas cultivadas em substratos constituídos por adição de proporção do esterco de codorna. Estando este material apresentado alto teor de $\mathrm{Na}^{+}$. No presente estudo observou-se efeito semelhante aos de Trazzi et al. $(2012,2013)$.

Efeito individual $(\mathrm{p}<0,05)$ dos tipos de resíduos foi verificado para a variável NF (Tabela 2). As mudas de C. grandis cultivadas com COP apresentaram maiores médias de NF, em relação às cultivadas com o RES (Tabela 3). O uso de substratos formulados com esterco bovino resulta em respostas positivas no NF de mudas de espécies florestais, conforme reportado em mudas de Pithecellobium dulce (Roxb.) Benth. (Guimarães et al., 2013), Dipteryx alata Vog. (Costa et al., 2015), Myracrodruon urundeuva Allemão (Kratka e Correia, 2015), e Caesalpinia pulcherrima (Moreira, 2018). Em relação ao uso de resíduo da extração de fibras de Agave sisalana, o efeito negativo deste foi constatado para as mudas de Mimosa caesalpiniaefolia Benth (Lacerda et al., 2006) e Caesalpinia pulcherrima (Moreira, 2018), aos 90 dias após semeadura, em casa de vegetação.

Houve efeito individual dos tipos $(\mathrm{P}<0,05)$ e das proporções de resíduos $(\mathrm{P}<0,01)$ para a variável comprimento da raiz (CR) (Tabela 2). Entre os tipos de resíduos, destacou-se o COP, quando comparados ao RES (Tabela 3). As maiores médias de CR obtidas nas plantas cultivadas com COP podem ser atribuídas pelas características físicas e químicas dos resíduos orgânicos. Embora o RES apresente maior disponibilidade dos nutrientes, baixa densidade (Tabela 1) para o crescimento e desenvolvimento da planta, este resíduo apresenta $\mathrm{pH}$ alto (Tabela 1) e com isso diminui a disponibilidade dos macronutrientes. Os altos teores de sais solúveis podem também provocar a queima ou necrose das raízes, sendo resultante das condições do próprio substrato ou do excesso de adubação (Prado, 2008). A adição do RES na formulação do substrato de cultivo pode ter contribuído para a elevação do $\mathrm{pH}$, e consequentemente, diminui a disponibilidade da espécie em suprir suas necessidades de determinados nutrientes e ainda deve-se considerar que o material

Tabela 3 - Médias de número de folhas (NF), comprimento da raiz (CR) e relação da massa seca da parte aérea entre a massa seca da raiz (MSPA/ MSR) de mudas de Cassia grandis L.f aos 90 dias após a semeadura, cultivadas em diferentes tipos de resíduos orgânicos [COP (composto orgânico de poda de árvore e esterco bovino e caprino) e RES (resíduo da extração de fibras de Agave sisalana)]

\begin{tabular}{cccc}
\hline \multirow{2}{*}{ Resíduo } & \multicolumn{3}{c}{ Médias } \\
\cline { 2 - 4 } & $\mathrm{NF}$ & $\mathrm{CR}$ & MSPA/MSR \\
\hline COP & $4,7 \mathrm{a}$ & $21,3 \mathrm{a}$ & $1,28 \mathrm{~b}$ \\
RES & $4,0 \mathrm{~b}$ & $18,9 \mathrm{~b}$ & $1,44 \mathrm{a}$ \\
CV $(\%)$ & 22,87 & 22,04 & 16,55 \\
\hline
\end{tabular}

Médias seguidas de mesma letra na coluna não diferem entre si, pelo teste F. 
estava apenas pré-fermentado e não sofreu o processo de compostagem tal como o composto orgânico (COP).

Deve-se considerar que um dos fatores que possibilitou maior incremento do $\mathrm{CR}$ em $\mathrm{COP}$ foi o fornecimento do micronutriente boro (B) (Tabela 1). No entanto, as concentrações ou atividades das formas iônicas deste elemento na solução do solo, que são usadas pelas plantas, são bastante dependentes do $\mathrm{pH}$, e sua disponibilidade é maior em $\mathrm{pH}$ menor que 6,0 (Ruara et al., 2009). Com base nesses fundamentos, o COP apresenta valor do $\mathrm{pH}$ (Tabela 1) próximo ao considerado adequado, o que permitiu melhor absorção desse micronutriente. A ação do B estimula a atividade meristemática das células e causa o alongamento e a diferenciação das raízes (Cunha et al., 2010).

Em estudos realizados com mudas de Schinus terebinthifolius foi verificado maior incremento de CR em substratos compostos por $100 \%$ de composto orgânico tendo em sua composição $(50 \%$ de terra de subsolo $+30 \%$ de esterco bovino $+20 \%$ de casca de arroz carbonizada) (Caldeira et al., 2008). Em outro estudo com mudas de Pithecellobium dulce (Roxb.) Benth, foi observado incremento no $\mathrm{CR}\left(39,7 \mathrm{~cm}\right.$ planta $\left.^{-1}\right) \mathrm{em}$ substratos que continha em sua composição solo + esterco (2:1 v/ v) (Guimarães et al., 2013). Para a espécie Anadenanthera macrocarpa (Benth) Brenae também foi relatado incremento na produção de raízes quando cultivadas em substrato contendo esterco de caprino (Ó et al., 2015).

As mudas de C. grandis quando cultivadas em substratos compostos apenas por solo apresentaram maior CR $\left(28,0 \mathrm{~cm}_{\text {planta }}{ }^{-1}\right)$, apresentando $56 \%$ maior incremento de raiz ao comparar com as cultivadas em substratos com maior proporção de resíduo $(12,2 \mathrm{~cm}$ planta $^{-1}$ ) (Figura 2). Este fato corrobora ao trabalho de Moreira (2016), que relatam efeito no CR em mudas de Caesalpinia pulcherrima cultivadas em substratos compostos apenas com o solo, aos 90 dias após a semeadura, sob condições controladas. O mesmo autor observa que o Neossolo Quartzarênico apresenta baixo teor de $\mathrm{P}$ disponível, sugerindo a busca da raiz pelo nutriente pouco móvel e proporcionando maior CR.

Em relação à massa seca das mudas, verificouse interação entre os tipos de resíduos e suas proporções $(\mathrm{P}<0,05)$ para massa seca da parte aérea (MSPA), $(\mathrm{P}<0,01)$ para massa seca da raiz (MSR) e $(\mathrm{P}<0,01)$ para massa seca total (MST) (Tabela 2). Mudas cultivadas em substrato constituído por apenas solo apresentaram

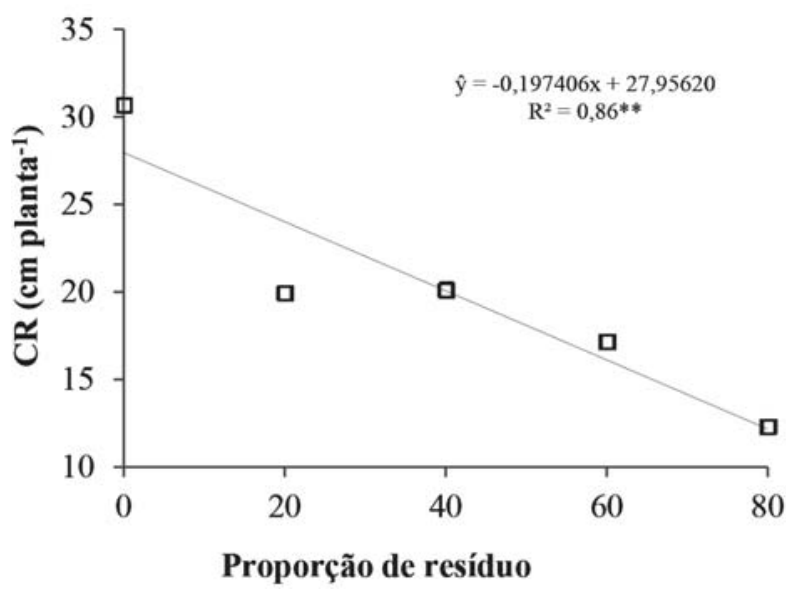

Figura 2 - Comprimento da raiz (CR) de mudas de Cassia grandis L. f, aos 90 dias após a semeadura, cultivadas em diferentes proporções de resíduo.

maior MSPA 0,84 g planta $^{-1}$ (Figura 3A), 0,69 g planta $^{-1}$ de MSR (Figura 3B) e 1,1 g planta $^{-1}$ de MST (Figura 3C). A adição dos resíduos COP ou RES resultou em decréscimo linear da produção de massa seca das mudas (Figura 3A, 3B, 3C). Esses resultados são similares aos reportados para mudas de Myracrodruon urundeuva Allemão (Krakta \& Correia, 2015), Hymenaea stigonocarpa (Lustosa Filho et al., 2015) Eugenia dysenterica DC, Hancornia speciosa Gomes e Dipteryx alata Vog (Paiva Sobrinho et al., 2010).

Verificou-se efeito individual $(\mathrm{p}<0,01)$ dos tipos e proporções de resíduos para a relação MSPA/MSR (Tabela 2). Em relação aos resíduos, o COP apresentou menores valores para esta variável em comparação ao RES (Tabela 3). Segundo Caldeira et al. (2013) e Gomes et al. (2013), valores muito altos para essa relação podem ser prejudiciais à muda, devido à tendência de desequilíbrio no crescimento e consequente, tombamento das mudas e possíveis problemas no que se refere à absorção de água para a parte aérea. Plantas cultivadas em apenas solo apresentaram melhor distribuição das massas (Figura 4). As mudas de C. grandis quando cultivadas com adição de resíduo ao substrato apresentam 32,61\% maior índice da MSPA/MSR, com comportamento quadrático, obtendo uma relação máxima estimada de 1,31 (planta $\left.{ }^{-1}\right)$ (Figura 4).

Caldeira et al. (2008) define que, o bom equilíbrio do crescimento entre a parte aérea e radicular deve 

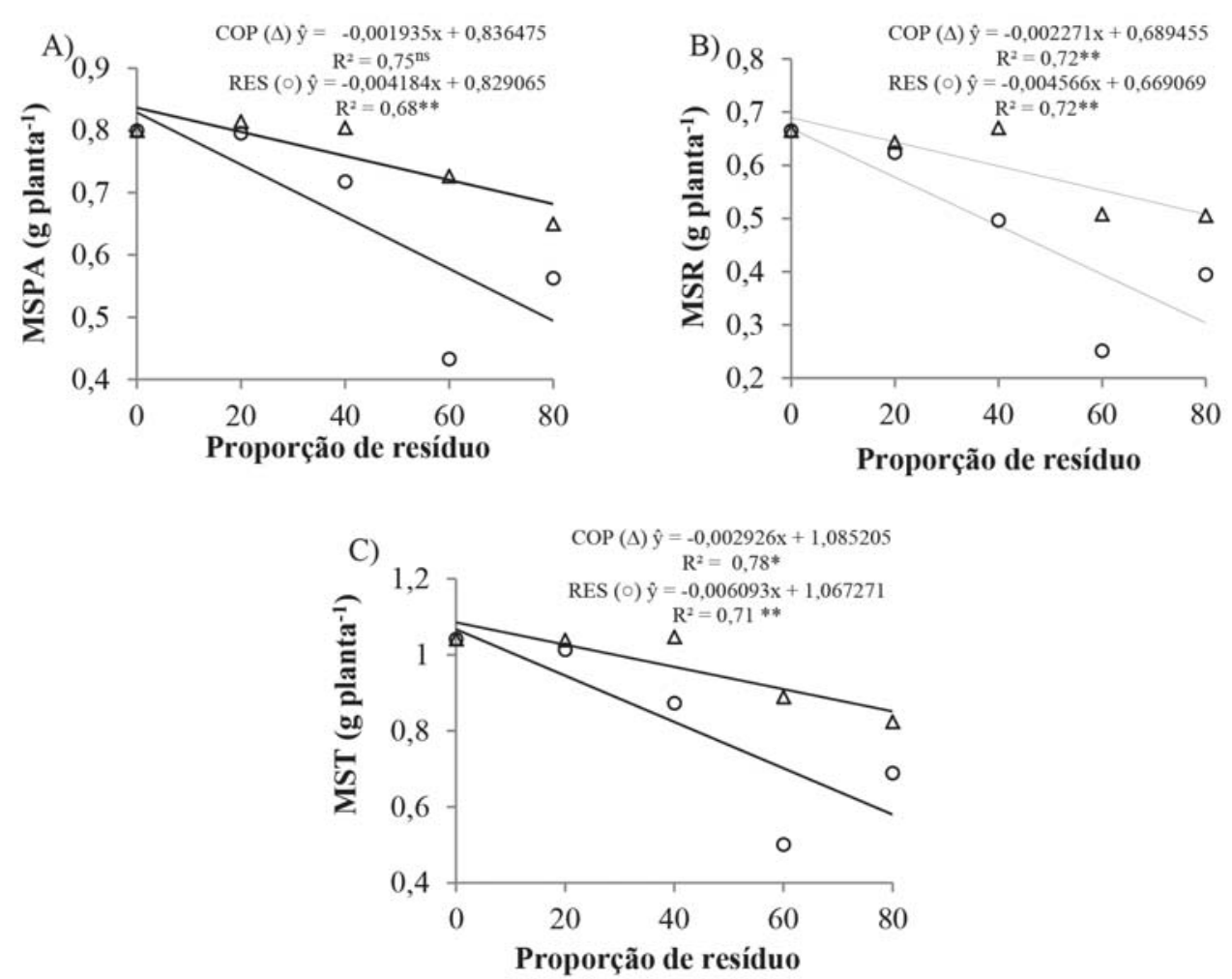

Figura 3 - (A) Massa seca da parte aérea (MSPA), (B) massa seca da raiz (MSR) e (C) massa seca total (MST) de mudas de Cassia grandis L. f, aos 90 dias após a semeadura, cultivadas em diferentes tipos e proporções de resíduos (COP (“) - composto orgânico de poda de árvore e esterco bovino e caprino; RES (Ё\%) - Resíduo da extração de fibras de Agave sisalana).

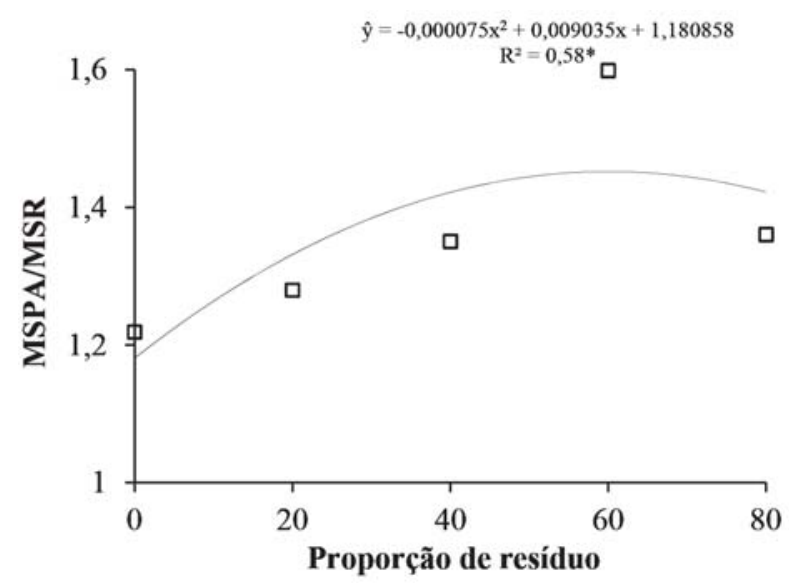

Figura 4 - Relação entre massa seca da parte aérea e massa seca de raízes (MSPA/MSR) de mudas de Cassia grandis L. f, aos 90 dias após a semeadura, cultivadas em diferentes proporções. ser próximo a 2,0, para a espécie Schinus terebinthifolius. De acordo com Duarte (2016), em estudos com mudas de C. grandis encontrou índices próximos a 2,0 em mudas cultivadas em tubetes com 50 e $120 \mathrm{~cm}^{3}$ de capacidade, após 90 dias de semeadura, sob condições controladas. Baseado nessas informações, no presente estudo, todas as plantas apresentaram índices próximo a 2,0 .

Houve interação $(\mathrm{P}<0,01)$ entre os tipos de resíduos e proporções para a variável H/MSPA (Tabela 2). Observou-se comportamento linear crescente a adição de RES ao substrato. Já o substrato composto por COP verificou-se que não houve efeito $(\mathrm{P}>0,05) \mathrm{em}$ mudas de C. grandis para essa variável (Figura 5). De acordo com Gomes et al. (2002), quanto menor for esse índice mais rústica será a muda e maior deverá ser a sua capacidade de sobrevivência no campo. No presente estudo observou-se que o substrato de cultivo que 
apresentou melhor índice constituiu-se de apenas solo, apresentando maior probabilidade de sobrevivência das mudas de C. grandis no campo.

Em mudas Sesbania virgata, houve um efeito semelhante para esse índice. À medida que se adicionou palha de arroz no substrato de cultivo, houve efeito negativo deste resíduo na qualidade da muda, indicando uma desproporção entre as duas variáveis, pois o crescimento não foi acompanhado pelo ganho de massa foliar (Sousa et al., 2015).

Diversos trabalhos com produção de mudas utiliza o IQD para recomendação de melhor proporção entre os componentes e formulação de substratos de cultivo. Efeitos positivos de substratos alternativos foram reportados para as espécies Sesbania virgata (Sousa et al., 2015), Pithecellobium dulce (Guimarães et al., 2013), Bauhinia forficata (Duarte \& Nunes et al., 2012), Chamaecrista desvauxii (Caldeira et al., 2013).

Observou-se interação $(\mathrm{p}<0,05)$ entre os tipos de resíduos e proporções para o IQD (Tabela 2) com comportamento linear decrescente (Figura 6). As mudas de $C$. grandis cultivadas em substratos com adição de resíduos não apresentaram respostas positivas ao

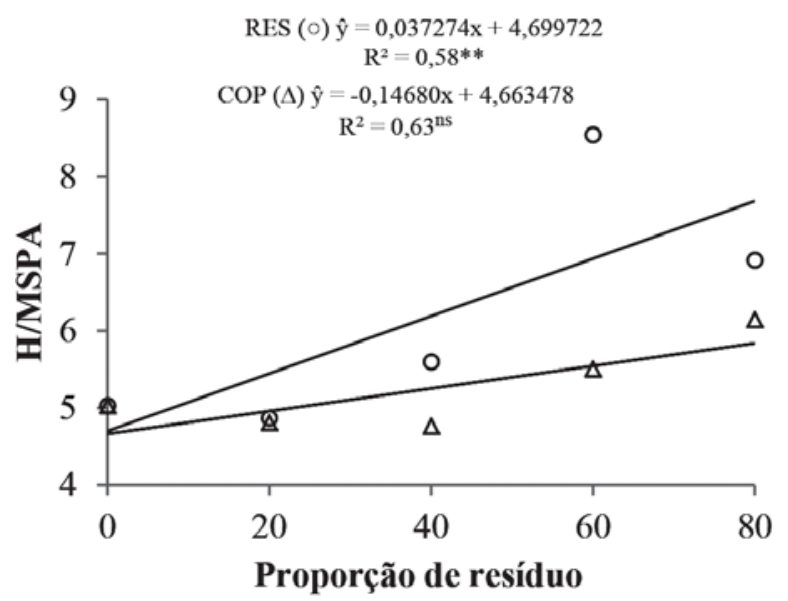

Figura 5 - Relação entre altura e massa seca da parte aérea (H/MSPA) de mudas de Cassia grandis L. f, aos 90 dias após a semeadura, cultivadas em diferentes proporções e tipos de resíduos (COP (") - Composto orgânico de poda de árvore e esterco bovino e caprino; RES (Ё\%) - Resíduo da extração de fibras de Agave sisalana).

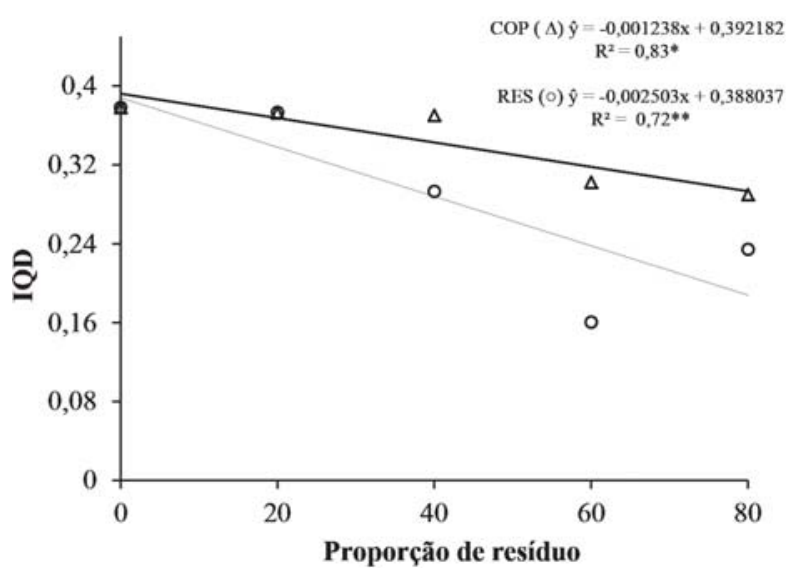

Figura 6 - Índice de qualidade de Dickson (IQD) de mudas de Cassia grandis L. f, aos 90 dias após a semeadura, cultivadas em diferentes tipos e proporções de resíduos (COP (“) Composto orgânico de poda de árvore e esterco bovino e caprino; RES (Ё\%)-Resíduo da extração de fibras de Agave sisalana).

IQD. Melhores índices foram observados em mudas cultivadas em apenas solo (0:100 resíduo:solo, v/v) (Figura 6).

Os resultados deste trabalho apontaram que mudas de $C$. grandis apresentaram melhor qualidade quando cultivadas em substrato constituído por apenas solo. Para esta espécie a adição de resíduos orgânicos constituídos de fibras de Agave sisalana e oriundo da compostagem de poda de árvores e jardins com esterco bovino e caprino, ao substrato de cultivo não é indicado para produção de mudas, devido à redução da variável IQD

C. grandis cresce naturalmente em solos com condições ácidas (Freitas et al., 2017). Com isto, nossos dados confirmam a capacidade da espécie em se desenvolver em solos de baixa fertilidade. Tal característica é importante para a utilização desta espécie em pesquisas para recuperação de áreas degradadas, uma vez que, os solos desses ambientes são, na maioria das vezes, de baixa fertilidade.

\section{CONCLUSÕES}

O uso de substratos constituídos por qualquer proporção de resíduo da extração de fibras de Agave sisalana ou de composto orgânico de poda de árvore 
acrescido de esterco bovino e caprino, acondicionados a Neossolo Quartzarênico não promovem efeito no crescimento inicial de Cassia grandis L. f.

As mudas de Cassia grandis L. f cultivadas em substrato constituído por apenas Neossolo Quartzarênico apresentam melhor resposta em todas variáveis analisadas.

\section{LITERATURA CITADA}

BEZERRA, F.T.C.; ANDRADE L.A.; BEZERRA, M.A.F. et al. Biometria de frutos e sementes e tratamentos pré-germinativos em Cassia grandis L. f. (Fabaceae). Semina: Ciências

Agrárias, v.33, n.1, p.2863-2876, 2012.

CALDEIRA, M.V.W.; DELARMELINA, W.M.; FARIA, J.C.T. et al. Substratos alternativos na produção de mudas de Chamaecrista desvauxii. Revista Árvore, v.37, n.1, p.31-39, 2013.

CALDEIRA, M.V.W.; ROSA, G.N.; FENILLI, T.A.B. et al. Composto orgânico na produção de mudas de aroeira-vermelha. Scientia Agraria, v.9, n.1, p.027-033, 2008.

COSTA, E.; DIAS, J.G.; LOPES, K.G. et al. Telas de sombreamento e substratos na produção de mudas de Dipteryx alata Vog. Floresta e Ambiente, v.22, n.3, p.416-425, 2015.

CUNHA, A.C.M.M.; PAIVA, H.N.; XAVIER, A. et al. Papel da nutrição mineral na formação de raízes adventícias em plantas lenhosas. Pesquisa Florestal Brasileira, n.58, p.35, 2010.

DELARMELINA, W.M.; CALDEIRA, M.V.W.; FARIA, J.C.T. et al. Diferentes substratos para a produção de mudas de Sesbania virgata.

Floresta e Ambiente, v.21, n.2, p.224-233, 2014.

DICKSON, A.; LEAF, A.L.; HOSNER, J.F. Quality appraisal of white spruce and white pine seedling stock in nurseries. Forest Chronicle, v.36, p.10-13, 1960.

DUARTE, D.M.; NUNES, U.R. Crescimento inicial de mudas de Bauhinia forficata Link em diferentes substratos. Cerne, v.18, n.2, p.327334, 2012.
DUARTE, M.L. Tubetes e substratos na produção de mudas de cássia-rosa (Cassia grandis Lf) e canafístula (Cassia ferruginea (Schrad.) Schrader ex DC). Dissertação (Mestrado em Ciência Florestal). Viçosa, MG: UFV, 2016. 57p.

FERNANDES, M.R.M.; NÓBREGA, R. S. A.; FERNANDES, M.M.; SOUSA, W.C.; LUSTOSA FILHO, J.F. Substratos e inoculação com Bradyrhizobium no crescimento de tamboril (Enterolobium contortisiliquum) em área degradada. Revista Agrarian, v.10, p.52-60, 2017.

FERREIRA, D.F. Sisvar: A guide for its bootstrap procedures in multiple comparisons. Ciência e Agrotecnologia, v.38, p.109-112, 2014.

FERREIRA, M.C.; COSTA, S.M.L.; PASIN, L.A.A. Uso de resíduos da agroindústria de bananas na composição de substratos para produção de mudas de pau pereira. Nativa, v.3, n.2, p.120124, 2015.

FREITAS, E.C.S.; PAIVA, H.N.; LEITE, H.G.; NETO, S.N.O. Crescimento e qualidade de mudas de Cassia Grandis Linnaeus f. em resposta à adubação fosfatada e calagem. Ciência Florestal, v.27, n.2, p.509-519, 2017.

GOMES, D.R.; CALDEIRA, M.V.W.; DELARMELINA, W.M. et al. Lodo de esgoto como substrato para produção de mudas de Tectona grandis L. Cerne, v.19, n.1, p.123-131, 2013.

GOMES, J.M.; COUTO, L.; LEITE, H.G et al. Parâmetros morfológicos na avaliação de qualidade de mudas de Eucalyptus grandis. Revista Árvore, v.26, n.6, p.655-664, 2002.

GUIMARÃES, I.P.; PEREIRA, F.E.C.B.; TORRES, S.B. et al. Produção de mudas de Pithecellobium dulce (Roxb.) Benth. em diferentes substratos.

Revista Ciências Agrarias, v.56, n.4, p.331337, 2013.

HIGASHIKAWA F.S. Caracterização físicoquímica de substratos produzidos a partir de combinações de resíduos orgânicos. Dissertação (Mestrado em Ciência) Lavras, MG: UFLA, 2009. 54p. 
KRATKA, P.C.; CORREIA, C.R.M. A. Crescimento inicial de aroeira do sertão (Myracrodruon urundeuva allemão) em diferentes substratos. Revista Árvore, v.39, n.3, p.551-559, 2015.

LACERDA, M.R.B.; PASSOS, M.A.; RODRIGUES, J.J.V. et al. Características físicas e químicas de substratos à base de pó de coco e resíduo de sisal para produção de mudas de sabiá (Mimosa caesalpiniaefolia Benth). Revista Árvore, v.30, n.2, p.163-170, 2006 .

LORENZI, H. Árvores brasileiras: manual de identificação e cultivo de plantas arbóreas nativas do Brasil. Nova Odessa: Instituto Plantarum, 5ed, v.1, p.54. 2008.

LUSTOSA FILHO, J.F.; NOBREGA, J.C.A.; NOBREGA, R.S.A. et al. Influence of organic substrates on growth and nutrient contents of jatobá (Hymenaea stigonocarpa). African Journal of Agricultural Research, v.10, n.26, p.2544-2552, 2015.

MELO, L.A.; ASSIS PEREIRA, G.; MOREIRA, E.J.C. et al. Crescimento de mudas de Eucalyptus grandis e Eremanthus erythropappus sob diferentes formulações de substrato. Floresta e Ambiente, v.21, n.2, p.234-242, 2014.

MOREIRA, F.M. Substratos orgânicos na produção de mudas arbóreas. Dissertação (Mestrado em Solos e Qualidade de Ecossistemas) Cruz das Almas, BA: UFRB, 2016. 64p.

Ó, K.D.S.; SILVA, G.H.; SANTOS, R.V. Crescimento inicial de angico em substratos com co-produtos de mineração e matéria orgânica. Revista Verde de Agroecologia e Desenvolvimento Sustentável, v.10, n.1, p.178-186, 2015.

PAIVA SOBRINHO, S.; LUZ, P.B.; SILVEIRA, T.L.S. et al. Substratos na produção de mudas de três espécies arbóreas do cerrado. Revista Brasileira de Ciências Agrárias, v.5, n.2, p.238-243, 2010.
PEREIRA, D.S.; NÓBREGA, R.S.A.; FILHO, J.F.L. et al. Crescimento e nodulação natural de feijão-caupi em solos de mineração de chumbo adubados com resíduo de sisal. Revista Brasileira de Agropecuária Sustentável (RBAS), v.7, n.4, p.34-42, 2017.

PIZARRO, A.P.B.; FILHO, A.M.O; PARENTE, J.P. et al. O aproveitamento do resíduo da indústria do sisal no controle de larvas de mosquitos. Revista da Sociedade Brasileira de Medicina Tropical, v.32, n.1, p.23-29, 1999.

PRADO, R. M. Nutrição de Plantas. 1.ed. São Paulo: Editora UNESP, v.1. 300p., 2008.

RUARO, L.; NETO, V.D.C.L.; JÚNIOR, P.J.R. Influência do boro, de fontes de nitrogênio e do $\mathrm{pH}$ do solo no controle de hérnia das crucíferas causada por Plasmodiophora brassicae. Tropical Plant Pathology, v.34, n.4, p231-238, 2009.

SCHOSSLER, T.R.; MACHADO, D.M.; ZUFFO, A.M. et al. Salinidade: efeitos na fisiologia e na nutrição mineral de plantas. Enciclopédia Biosfera, v.8, n.15, p.1563-1578, 2012.

SILVA, A.G.; COSTA, L.G.; GOMES, D.R. et al. Testes para quebra de dormência de sementes de Cassia grandis L. f. e, morfologia de sementes, frutos e plântulas. Enciclopédia Biosfera, Centro Científico Conhecer, v.8, n.14, p.907-916, 2012.

SOUSA, L.B.; NÓBREGA, R.S.A.; LUSTOSA FILHO, J.F et al. Sesbania virgata (Cav. Pers) cultivation in different substrates. Revista de Ciências Agrárias/ Amazonian Journal of Agricultural and Environmental Sciences, v.58, n.3, p.240-247, 2015.

TRAZZI, P.A.; CALDEIRA, M.V.W.; COLOMBI, R. et al. Estercos de origem animal em substratos para a produção de mudas florestais: atributos físicos e químicos. Scientia Forestalis, v.40, n.96, p.455-462, 2012.

TRAZZI, P.A.; CALDEIRA, M.V.W.; PASSOS, R.R. et al. Substratos de origem orgânica para produção de mudas de teca (Tectona grandis Linn. F.). Ciência Florestal, v.23, n.3, p.401-409, 2013.

Recebido para publicação em 15/06/2018 e aprovado em 11/09/2018. 